\title{
Risk analysis as an integrated operational and legal instrument with respect to the safety of maritime traffic
}

\author{
Y. Koldenhof ${ }^{2}$, H. Nijsse ${ }^{3}$, C. Van der Tak ${ }^{2}$ \& C. C. Glansdorp ${ }^{1}$ \\ ${ }^{I}$ CETLE, Rotterdam, The Netherlands \\ ${ }^{2}$ MARIN Department MSCN, Wageningen, The Netherlands \\ ${ }^{3}$ Independent legal consultant, The Netherlands
}

\begin{abstract}
This paper emanates from the European Research Project MarNIS. The possibility of monitoring traffic has improved considerably since the introduction of AIS (Automatic Identification System). A much better view of what is going on at sea offers new possibilities to enhance shipping safety. The risk of each ship delivers the basis for taking measures according to UNCLOS and the precautionary principle, to ships that have a far more than average risk. The application of this principle requires a scientific approach for the determination of the risk and new operational tools.

The three main aspects necessary to implement risk analysis into the maritime traffic to enhance safety at sea are described. Firstly, the legal basis - the need for legal instruments, the definition of a high risk ship and new public competences. Secondly, a mathematical model to determine the so-called risk index for individual ships calculated dynamically, depending on the geographical position, the ship characteristics, the environmental conditions, other ships, shallows and other obstacles, such as offshore platforms and wind farms. Thirdly, there is the operational application.
\end{abstract}

Keywords: risk approach, risk index, maritime safety.

\section{Introduction}

The possibility of monitoring traffic and the quality of the response to incidents has improved considerably with the introduction of AIS (Automatic 
Identification System). Important benefits are the quality of the traffic image, helping to find ships that can be requested for first line response and the decrease of the response time with respect to SAR (Search and Rescue). However, the AIS can even offer more when it is used in a more pro-active way, to reduce the probability of an incident, hence reducing the risk. For this purpose, the risk of each ship is dynamically calculated with a risk module based on the data in an AIS message, namely the environmental conditions. The result of the risk calculation, the risk index, is linked to the AIS-target. This risk awareness facilitates the task of an operator because he can give more attention to these more risk alert ships.

Apart from awareness, a vessel that demonstrates far more than an average risk can be subjected to measures according to UNCLOS and the precautionary principle that is accepted by IMO and the European Commission (Jarvis et al. [5]). Application of this principle requires a scientific approach of the risk method by the member States. Each Member State applies risk methods to a certain extent by applying FSA (Formal Safety Assessment) and FSA similar methods to reduce risk, primarily in ship design issues. IALA develops methods to reduce risks in channels marked with Aids to Navigation, but the concept of dynamic risk is not yet employed.

This paper is divided into three main topics, firstly the legal basis; the second part describes briefly the mathematical model used to determine the risk value for individual ships calculated dynamically, depending on the geographical position, the ship characteristics, the environmental conditions, other ships, shallows and other obstacles as offshore platforms and wind farms. Finally, the paper describes an example of an operational application of the risk model.

\section{Legal aspects}

\subsection{Development of international law}

In the last three decades the protection and preservation of the marine environment has become a political and a social issue, in particular with respect to maritime traffic. This has resulted in the development and expansion of international and of national law for the prevention of accidental vessel-source marine pollution. An example is the International Convention relating to Intervention on the High Seas in Cases of Oil Pollution Casualties [6], hereafter referred to as the Intervention Convention. This convention was adopted as a result of the Torrey Canyon incident in 1967 off the coast of England [7]. In a broader context, the United Nations Convention on the Law of the Sea (UNCLOS) [8], contains specific provisions relating to the "Protection and preservation of the marine environment" in its Part XII.

The danger and the impact of disasters in maritime traffic have risen as a result of the combined expansion of maritime transport of dangerous goods and size of ships, and substandard shipping. On the other hand, due to the development of information technology, coastal authorities (can) have more and more information about ships and their cargo, the actual maritime traffic in an 
area as well as numerous other types of data. In addition, equipment on board of ships, such as Automatic Identification Systems (AIS) makes it possible for information to be (automatically) transferred to Vessel Traffic Services (VTS) centres. VTS centres are evolving from fulfilling a mere role of traffic surveillance and transmission of information to ships to becoming maritime traffic management centres. VTS staff is competent to form a professional opinion as to the safety of maritime traffic in general and individual ships in particular, as well as to potential dangers for the marine environment.

The future logical, and desirable, development of this evolution is that VTS centres would be used not only for the management of maritime traffic, but also and expressly for the proactive application of UNCLOS to ensure the protection and preservation of the marine environment from maritime traffic in coastal areas. This would include in particular actions towards vessels presenting an actual high risk for the marine environment in the Exclusive Economic Zone (EEZ).

UNCLOS already allows coastal States, under certain circumstances, to intervene in their territorial sea towards a foreign vessel that is or may become a danger for the marine environment or the safety of navigation (see for instance Sage, "Precautionary Coastal States' Jurisdiction", 36 Ocean Development and International Law, forthcoming (2006)). By the same token, if there is a reasonable suspicion that a vessel is or, may become a danger for the environment beyond the territorial sea it is arguable that a coastal State should have the means and powers to intervene, not only after an incident, but - and more importantly - just before an incident, on time to prevent it .

The question is reformulated as follows:

"Is it possible under international law that the competent authority of a coastal State may intervene towards an individual foreign vessel in the EEZ, beyond the territorial sea, if there is a reasonable ground to believe that this vessel under the actual circumstances is or may cause a more than average risk for the environment; and, if yes, can the coastal States take intervention measures such as (navigational) instruction and/or, if necessary, physical measures such as compulsory assistance of tug boats or compulsory pilotage?"

\subsection{The Precautionary Principle}

The Precautionary Principle has already a history of some decades. For the implementation of the MarNIS concept we have restrict ourselves to the relevant development of the Precautionary Principle.

An important step was the Rio Declaration on Environment and Development of the United Nations Conference on Environment and Development at Rio de Janeiro from 3 to 14 June 1992 [9], in particular Principle 15 that says:

"In order to protect the environment, the precautionary approach shall be widely applied by States according to their capabilities. Where there are threats or serious irreversible damage, lack of full scientific certainty shall not be used as a reason for postponing cost-effective measures to prevent environmental degradation." 


\subsubsection{The application of the precautionary principle by the $\mathbf{E U}$}

The European Commission adopted in 2000 the "Communication from the Commission on the precautionary principle" [10].

Where action is deemed necessary, measures based on the precautionary principle should be, inter alia:

- proportional to the chosen level of protection;

- non-discriminatory in their application;

- consistent with similar measures already taken;

- $\quad$ based on an examination of the potential benefits and costs of action or lack of action;

- $\quad$ subject to review, in the light of new scientific data; and

- capable of assigning responsibility for producing the scientific evidence necessary for a more comprehensive risk management.

The view of the Commission on the precautionary principle has been endorsed by the Council in December 2000.

The precautionary principle is, as principle of Community policy, implemented in the EU Treaty [11].

Article 174, paragraph 1, states:

Community policy on the environment shall contribute to pursuit of the following objectives:

- $\quad$ preserving, protecting and improving the quality of the environment;

- $\quad$ protecting human health;

- $\quad$ prudent and rational utilisation of natural resources;

- $\quad$ promoting measures at international level to deal with regional or worldwide environmental problems.

Article 174, paragraph 2, states:

"Community policy on the environment shall aim at a high level of protection taking into account the diversity of situations in the various regions of the Community. It shall be based on the precautionary principle and on the principles that preventive action should be taken, that environmental damage should as a priority be rectified at source and that the polluter shall pay."

\subsection{Review of the proposals of the MarNIS concept with respect to high risk ships regarding EU policy on the precautionary principle}

The proposals with respect to high risk ships comply with the view of the Commission on the precautionary principle and can be considered as the application of article 174, paragraph 1 and paragraph 2, and in accordance with the articles 194, 197 and 237 of UNCLOS.

The identification and designation of a ship as a high risk ship can only be founded on the existence of actual facts or circumstances which can be considered as implying more than an average risk, based on, as much as possible, generally accepted rules and standards, including a scientific method of risk analysis. The criteria for the determination of jurisdiction in the different areas are restricted to and will be in accordance with international law (UNCLOS), in particular with respect to the provisions for the territorial waters, the contiguous 
zone and the area of the EEZ (see the MarNIS Paper "Legal aspects for the implementation of the MarNIS concept", paragraph 4.1).

There are scientific methods of risk analysis developed with respect to maritime traffic, also in the MarNIS project (see the report of MarNIS Work Package 3.1). These methods will be - as much as possible and in accordance with the view of the Commission - the base and used for risk assessment, risk management and risk communication.

\subsection{Recommendations for the legal elements of high risk ships}

In summary, the following recommendations with respect the legal elements in support of High Risk Ships are considered:

- A competent authority can designate a ship as a High Risk Ship if it is located within:

$\circ$ the Territorial Sea, and if the passage of that ship is or will be not innocent in the sense of article 19, paragraph 2, of UNCLOS, or if that ship is or can be a threat for the subjects as referred to in article 21, paragraph 1, of UNCLOS;

$\circ$ the Contiguous Zone in the sense of article 33 of UNCLOS, and if it is necessary to prevent infringements of customs, fiscal, immigration or sanitary laws;

$\circ$ the Exclusive Economic Zone in the sense of article 55 of UNCLOS and if that ship is, can or will become a threat to the protection and preservation of the marine or coastal environment;

$\circ$ the Search and Rescue Region as referred to in the International Convention on Maritime Search and Rescue of 1979, and if it is entitled according to international law to take measures.

- A designation of a ship as a High Risk Ship can only be based on facts or circumstances as instantaneous weather conditions, failures regarding that ship, its machinery, equipment, cargo or crew, or any act, which can be considered as implying more than an average risk, based on, as much as possible, generally accepted rules and standards, including a scientific method of risk analysis;

- A competent authority shall take all reasonable measures to inform the master of a ship forthwith of any decision as mentioned under the first bullet, except when there are legitimate grounds not to do so;

- Without prejudice to international law, competent authorities shall have the power to give instructions to the master to attain a certain navigational result and, in case of non compliance, the complementary power to take the necessary physical measures against a High Risk Ship to protect and preserve the marine and coastal environment and to prevent, reduce and control incidents and pollution at sea and to minimise their impact;

- The previous bullet applies equally to a ship in a designated area that, in accordance with international law, has been qualified, temporarily or permanently, as a special area for the protection and preservation of the marine environment. 


\section{A model for risk analysis for maritime traffic}

\subsection{Risk assessment}

Risk is defined as the probability of an accident multiplied with the possible consequences of that accident. A large passenger vessel can be considered as a relative high risk ship, even though it has the best crew and equipment on board, simply because of the fact that there are over 2000 people on board who will be in dangerous conditions if a serious accident happens. The same accounts for large oil tankers. On the other side a very old bulk carrier that sails under a flag of convenience according to the Paris MoU can also be considered as a relative high risk ship because the probability of an accident is relatively high, even though there is a small crew on board and the cargo on board is non pollutant except bunker oil.

To monitor the traffic in a more pro-active way and implement measures to reduce the risk means that there is a need for an objective way of finding the balance between the severity of the consequences and the probability of an accident. Using years of statistical accident data, expert opinions and mathematical modelling, a risk index for individual ships has been developed, first within the EMBARC-project (van der Tak and Glansdorp [1]) and further developed and demonstrated within the MarNIS-project (Koldenhof et al. [2]).

The calculation of the risk index consists of three main parts; the probability, the consequences and the implementation of risk control options. Finally, this will result in one risk index in a monetary unit per unit time.

\subsubsection{Probability}

One part of the risk value of an individual ship is the probability of an accident for that ship on the given time and location. Different types of (nautical) accidents are taken into account when calculating the risk value:

- Collision (CN) between two moving vessels;

- $\quad$ Foundering (FD); the incident that a ships sinks due to the environmental conditions;

- Hull failure (HH); the probability that a hole will occur in the hull of a ship;

- Machinery failure (MM); a failure that results in a drifting ship;

- Fire/explosion (FX) on board;

- A ramming contact; a contact with an object, coastline or grounding due to a navigational error;

- A drifting contact; a contact with an object, coastline or grounding due to a machinery failure;

The probability of each type of accident depends on different influencing factors:

- Ship characteristics

○ Type, size and age of the ship

- The navigational status of the ship (e.g. sailing or Not Under Command)

○ Flag (Port State Control list, white, grey and black lists)

- Environmental conditions 
Table 1: $\quad$ Accident types and the corresponding exposures.

\begin{tabular}{|c|c|}
\hline Accident type & Exposure \\
\hline Collision & Encounter \\
\hline Foundering & Nautical miles \\
\hline Hull failure & Nautical miles \\
\hline Machinery failure & Nautical miles \\
\hline Fire/Explosions & Nautical miles \\
\hline Ramming contact & Ramming Opportunity \\
\hline Drifting contact & Stranding Opportunity \\
\hline
\end{tabular}

$\circ$ wind (Beaufort and direction); visibility; current

$\circ$ other traffic

○ layout/coastline

The accident probability for an individual ship is determined using so-called exposures and a casualty rate. The exposures are the number of potential accident sensitive situations in which a ship can be involved that could lead to an accident. For example, for the accident type collision the exposure is an encounter between two ships. By relating these exposures with the actual casualties from the accident database, the so-called casualty rates for the different accident types are derived.

The different exposures are determined taking into account different factors and mathematical models. The different exposures are described in detail in (Koldenhof et al. [2] and Koldenhof et al. [4]). The calculated exposures are multiplied with the so-called casualty rate (CASRAT). The casualty rate is the probability that a predefined exposure type will lead to a real accident. So it is, for example, the probability that an encounter, as defined within the model, will lead to a real collision. This "static" casualty rate is determined using accident data from 1990-2005.

By multiplying the calculated exposure and the static casualty rate, an average probability is determined. To include the influence of different factors, such as wind, visibility and flag of the ship, the average level of the probability is multiplied with different factors to incorporate the influence of the different factors.

$$
\mathrm{P}_{\text {accident }}(i)=\left(\mathrm{F}_{\text {flag }} * \mathrm{~F}_{\text {age }} * \mathrm{~F}_{\text {wind }} * \mathrm{~F}_{\mathrm{vis}} * \mathrm{~F}_{\text {nav }}\right) * \operatorname{EXP}(i) *
$$

where:

EXP(i) Exposure for a certain accident type (i)

CASRAT(i,type,size) Casualty rate for a certain accident type (i), ship type/size

$\mathrm{F}_{\text {flag }} \quad$ multiplication factor for flag state

$\mathrm{F}_{\mathrm{age}} \quad$ multiplication factor for age of the ship

$\mathrm{F}_{\text {wind }} \quad$ multiplication factor for wind

$\mathrm{F}_{\mathrm{vis}} \quad$ multiplication factor for visibility

$\mathrm{F}_{\text {nav }} \quad$ multiplication factor for the navigation status

$\mathrm{P}_{\text {accident }}(\mathrm{i}) \quad$ the probability of an accident type (i) 


\section{Validation}

Within MarNIS the multiplication model as shown before is validated by INRETS (Degré and Muller 2006, [3]).

\subsection{Consequences}

The consequences of an accident at sea can be divided into three main categories:

- Consequences for life

- Consequences for the environment; pollution

- Structural consequences.

The consequences are very important and the possible consequences vary with the type of casualty. For example, the consequences after a machinery failure are negligible as long as the incident occurs far enough from the coast. Such a casualty (or better incident) will only have consequences when the drifting ship strikes a rocky coast before an emergency towing vessel can arrive.

The consequences of a casualty can vary strongly, from little damage up to the case that the ship sinks as result of the casualty and the whole crew and all passengers become in distress. Another scenario is that a cargo tank or fuel tank is penetrated and an oil spill occurs, which threatens the coast. In consequence, calculations for several scenarios (from a small spill to a large spill with corresponding probabilities) are considered for which the costs are estimated. The ship type and size plays an important role with respect to the number of persons at risk and the probability and size of an oil spill.

The draught of the ship is an indication of the amount of cargo on board. In future when some global information is known about the type of oil (from SafeSeaNet, AIS or other sources) the pollution risk model can be improved.

The casualties with the highest cost levels are those where the ship sinks after the casualty. This category is considered as a separate scenario in the consequence calculations.

Influencing factors:

- Ship characteristics:

- Amount of cargo/fuel oil ; type of oil;

- Number of crew/passengers

- Geographical layout:

○ Distance to the coast; type of coast;

○ Wind force (Beaufort); wind direction; current

- Risk Control Options :

- Location/capacity SAR (Search and Rescue);

o Location/capacity OPRC (Oil Pollution Response Coordination);

o Location ETV (Emergency Towing Vessel).

Depending on the type of consequences, three different risk values are calculated: Loss of Life - Pollution - and Structural Risk Index. The total risk index is the sum of the three risk values. 


\section{Operational applications}

A risk approach is followed to select the ships in, a monitoring area, which require more attention. This risk approach means that the potential risk is calculated for all ships present in a monitoring area. In addition to this risk approach, the operator must have the opportunity to select some ships that have to be followed, f. e. ships that show suspicious behaviour or ships that have communication problems. In this paragraph, the "operation" process regarding the identifying of an Alert and High Risk ship is described briefly.

\subsection{Operational process to determine an alert and a high risk ship}

The general process to determine an alert and high risk ship can be described in 4 different steps:

\section{Step 1: Calculating the alert value}

Using the model a briefly described above the alert value (individual risk index) is calculated based on the present situation.

\section{Step 2: Compare the Alert Value with a threshold}

The calculated alert value of each ship in the area is compared with a given, predefined threshold. This threshold may vary due to weather conditions.

\section{Step 3: Automatic Assignment of an Alert Ship}

When the alert value of a ship is above the given threshold, the ship will be assigned as an Alert Ship. This process will be done automatically by the software. An Alert Ship does not have any legal status. As a consequence, the operator (in his role as representative of the competent authority) does not possess the power to take action and give instructions towards the ship that could interfere with her right of free passage, when at the high seas. The Alert status can be used to take so-called "on-shore" risk control options, these are measures that an operator can always take and do not affect the ships right of free passage, e.g. send out an Emergency Towing Vessel (ETV). So the Alert Status can help the operator to make certain pro-active decisions that could help to reduce the risk. Because the highs with a relative high risk are visible on the screen the operator is more aware of these vessels, and can monitor on a more effective way.

\section{Step 4: Assign qualification "High Risk Ship"}

Based on procedures and legislation the competent authority may designate a ship as High Risk Ship. The operator could receive extra information about a (Alert) ship, which may lead to the decision to assign an Alert Ship as a High Risk Ship. A High Risk Ship has a formal legal status and provides the operator (as representative of the competent authority) with extra powers to act towards the ship, to take measures that could interfere with the ships right of free passages. The operator is now allowed to take so-called "off-shore" Risk Control Options such as rerouting or even stop a vessel. 


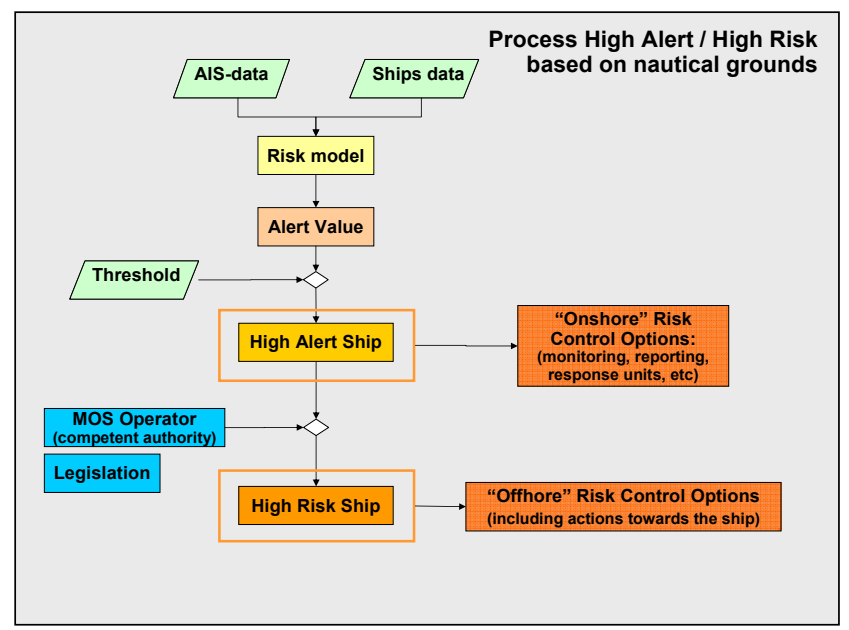

Figure 1: Overview decision process.

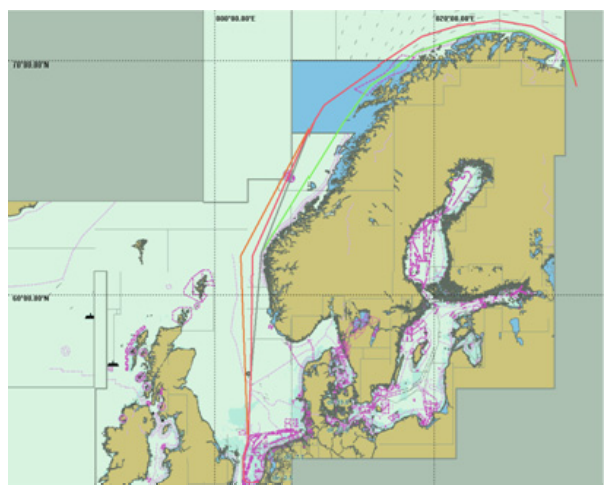

Figure 2: Overview of the Vardø TSS and three routes to the south.

When an operator decides to make an alert ship a HRS, the operator immediately informs the master of the vessel. The master acknowledges the message and should implement the route instructions of the operator, when they are issued.

\subsection{Strategic use of the model}

The model results can also be used in a more strategically way, e.g. to determine some rerouting measures. The method is applied for a route from the port of Murmansk to Rotterdam for a Liberian tanker of 106,000 tdw (built in 1996).

The route from Murmansk to the South is used by an increasing number of oil tankers. These tankers have the largest pollution threat for the Norwegian coast.

This growing transport volume was the main reason to introduce the VardøRøst TSS. The wind force and the wind direction are varied because these 
external weather conditions have the largest influence on the result of the calculations. Within the calculations, it is assumed that the wind condition will not change during the calculation. This means that a wind with a direction from the coast will not result in an oil pollution of the coast, thus an under estimation of the real pollution, but a wind direction to the coast will overestimate the pollution of the coast.

The extra distance that must be covered is given in column 2 of Table 2 When the distance from the coast is selected a long time before the vessel arrives at the decision point the extra distance can be kept at a minimum. Figure 3 shows the determination of the optimum distance from the coast for Beaufort 5 . The yellow line is an approximation of the total costs, which assists in finding the minimum of the total costs.

Table 2 shows information for Beaufort 8. The risk has increased and the speed is reduced to $77 \%$ of the still water speed due to the bad weather. As can be seen the risk is increased from 7 to $11 \%$.

By establishing the required "optimal" distance to the coast for the different weather conditions ships can be allowed take the "shorter" route when the weather is calm and will not be obliged to take the longer route.

Table 2: $\quad$ Calculation of the costs components for BF 8.

\begin{tabular}{|c|c|c|c|c|c|}
\hline $\begin{array}{c}\text { distance } \\
\text { from coast }\end{array}$ & $\begin{array}{c}\text { distance } \\
\text { in } \mathrm{nm}\end{array}$ & $\begin{array}{c}\text { risk costs } \\
\text { in } \mathrm{k} €\end{array}$ & $\begin{array}{c}\text { costs voyage } \\
\text { in } \mathrm{k} €\end{array}$ & $\begin{array}{c}\text { Total costs } \\
\text { in } \mathrm{k} €\end{array}$ & $\begin{array}{c}\text { Risk as } \\
\%\end{array}$ \\
\hline 5 & 1686 & 31.10 & 251.43 & 282.53 & 11.0 \\
\hline 30 & 1692 & 20.92 & 252.33 & 273.26 & 7.7 \\
\hline 60 & 1704 & 19.03 & 254.04 & 273.07 & 7.0 \\
\hline
\end{tabular}

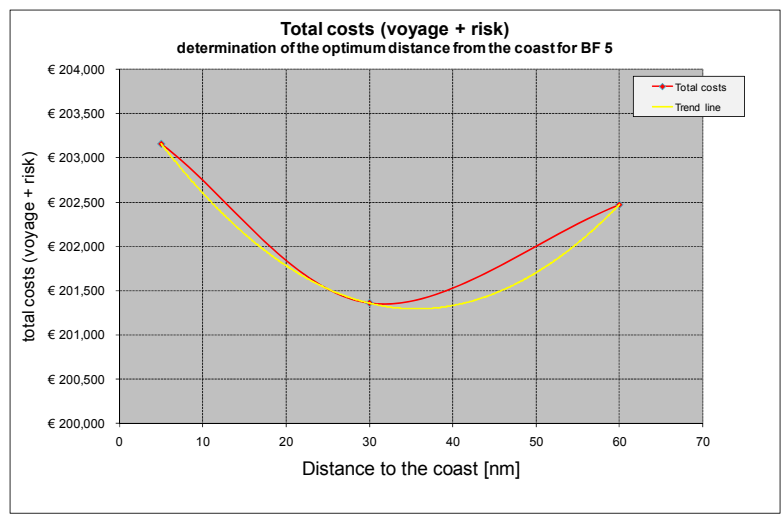

Figure 3: $\quad$ Determination of the optimum distance from the coast for BF 5. 


\section{Conclusions/recommendations}

The model and process described in this paper has been implemented in the MRCC of Milford Haven since June 2007. Firstly, there was some scepticism. A detailed explanation of the model behind the alert values was necessary before they understood what was presented on their screens.

However, a long time is expected to pass before the ideas behind the new possibilities will generally be accepted and applied in the decision process to take the necessary measures to enhance the safety of ships.

\section{References}

[1] Tak, C. van der \& Glansdorp, C.C. 2005. Vessel Traffic Management in European Waters, EMBARC Final Work Package 7 report,

[2] Koldenhof, Y et al. 2008. WP 3.1 Risk and Environmental Impact Analysis, http://www.marnis.org/.

[3] Degré, T. \& Muller, O. 2006. The use of risk concept to contribute to the design of a Risk Index and to characterize and select High Risk Vessels. MarNIS Interim Technical Research Report

[4] Koldenhof, Y, C van der Tak, C.C. Glansdorp. 2009 Risk Awareness; a model to calculate the risk of a ship dynamically. MTE09, www.marin.nl

[5] Jarvis, D.J. et al. 2009. Legal Aspects for the implementation of the MarNIS concept, MarNIS D-HA2E, 08/01/09, http: //www.marnis.org/.

[6] 1969 International Convention relating to Intervention on the High Seas in Cases of Oil Pollution Casualties, Brussels, 29 November 1969. In force 6 May 1975, UKTS 77 (1975).

[7] Dupuy - Vignes, A Handbook on the New Law of the Sea 2 (Publisher + Place of publication, 1991), p. 863.

[8] 1982 United Nations Convention on the Law of the Sea, Montego Bay, 10 December 1982. In force 16 November 1994, XX ILM 1245 (1982).

[9] Rio Declaration on Environment and Development, 14 June 1992, UN Doc. A/CONF.151/26 Rev.1, Report of the UNCED Vol. 1 (New York).

[10] COM (2000) 1, Brussels 02.02.2000.

[11] Consolidated versions of the Treaty on European Union and of the Treaty establishing the European Community, article 174; Official Journal of the European Union 29.12.2006, C 321. 